\title{
The Intricate Influence of the Placebo Effect on Medical Cannabis and Cannabinoids
}

\author{
Jürg Gertsch \\ Institute of Biochemistry and Molecular Medicine, University of Bern, Bern, Switzerland
}

\section{Keywords}

Cannabis · Cannabinoids $\cdot$ Placebo effect $\cdot$ THC $\cdot$ CBD

\begin{abstract}
The botanical drug cannabis flos (inflorescence of Cannabis sativa L.) has a unique popular status as being a potent recreational drug and bona fide universal remedy (panacea). Generally, cannabinoids exert therapeutic effects in a broad range of pathophysiologies related to inflammation, pain, metabolic and stress-related conditions in preclinical animal models. However, the translation of such data to humans still lacks an evidence-based foundation. Motivated by the booming cannabis manufacturing industry and the increasing worldwide self-therapy by patients, there are cumulative accounts about broad therapeutic effects of cannabis and legal cannabinoids like cannabidiol (CBD) beyond statistical evidence. The numerous affirming anecdotal reports by patients pose a challenge to physicians and legal authorities. Moreover, the lack of standardization of cannabis products and widely missing randomized double-blind placebo-controlled clinical trials largely hinder the scientific assessment of medical cannabis in humans. Given the recent insight that the endocannabinoid system is mediating, at least in part, a
\end{abstract}

placebo effect, psychoactive cannabis and cannabinoids could exert complex neuropharmacological actions. As discussed in this commentary, the meaning response may play a role in the broad palliative and therapeutic effects of medical cannabis unprecedented by other phytopharmaceuticals.

(c) 2018 The Author(s)

Published by S. Karger AG, Basel

According to the World Health Organization (WHO), an estimated $60-80 \%$ of the world's population employ medicinal plants as primary medicines [1]. More than 25,000 plants are used in the context of traditional or alternative medicine [2] and phytotherapy still constitutes an integral commodity of the health systems in developing countries [3]. For the great majority of medicinal plants, the underlying molecular mechanisms of action remain unknown, thus holding a promise for drug discovery [4]. From an evolutionary point of view, most plant secondary metabolites might be weak nonspecific modulators of mammalian proteins via our diet and execute chronic health benefits [5]. Like most medicines, botanical drugs can trigger placebo effects and thus represent ancient symbols of a meaning response (vide in-

\begin{tabular}{ll}
\hline KARGER & $\begin{array}{l}\text { ( ) } 2018 \text { The Author(s) } \\
\text { Published by S. Karger AG, Basel }\end{array}$ \\
E-Mail karger@karger.com & This article is licensed under the Creative Commons Attribution- \\
www.karger.com/mca & $\begin{array}{l}\text { NonCommercial-NoDerivatives 4.0 International License (CC BY- } \\
\text { NC-ND) (http://www.karger.com/Services/OpenAccessLicense). } \\
\text { Usage and distribution for commercial purposes as well as any dis- } \\
\text { tribution of modified material requires written permission. }\end{array}$
\end{tabular}

\section{KARGER}


fra), a term coined by Moerman and Jonas [6]. In Western medicine, a selected number of botanical drugs, primarily derived from the Dioscurides De Materia Medica, are listed in pharmacopoeias (e.g., Ph. Eur. or USP) [7]. Their use and health claims in Western medicine are subject to evidence-based medicine, thus requiring clinical prove of efficacy beyond the traditional anecdotal evidence [8]. Likewise, numerous medicinal plants and mixtures thereof are used as medicines in traditional Chinese medicine, which offers a complex dynamic system of alternative medicine [9]. Intriguingly, many patients who have access to Western medicine still favor botanical drugs because they are believed to have fewer side effects.

Psychoactive cannabis (Cannabis sativa L. and C. indica L.) was first mentioned as a herbal drug in the 1851 (3rd) edition of the US Pharmacopoeia (USP). Its ethnopharmacological use as a recreational drug originated in the Orient, from where it spread all over the world. Cannabis soon became very popular as a botanical drug in the West as general tonic with rather diffuse medical indications until it became an illegal drug in the 1930s [10]. Because of the profound psychedelic (i.e., recreational) nature of high doses of $\Delta^{9}$-tetrahydrocannabinol (THC), cannabis psychoactive chemovars containing high amounts of the THC acid precursor THCA were only marginally studied in a clinical context. In 1941, cannabis was removed from the USP and the National Formulary [10]. The revival of research on the medicinal properties of cannabis regained momentum after the discovery of the endocannabinoid system (ECS) in the 1990s [11-15], peaking in the current worldwide campaign to legalize this plant and its psychoactive constituents for medical purposes.

With the exception of Papaver somniferum L. (opium), no other botanical drug is equally renowned as cannabis for being a highly potent and efficacious phytopharmaceutical. Unlike with other medicinal plants that have rather questionable efficacies and unknown mechanisms of action, nobody seems to doubt a priori the therapeutic effectiveness of cannabis. Accordingly, patients who use medical cannabis products have high expectations of beneficial effects (i.e., the plant is meaningful to them). Opium and psychoactive cannabis have been used since millennia and both plants constitute important pillars of contemporary pharmacotherapies as their constituents led to the discovery of endogenous opiates and the ECS, respectively. Rather intriguingly, both botanical drugs activate psychoneuroimmunological mechanisms that have been shown to mediate placebo analgesia $[16,17]$. Thus, in addition to having more general tissue effects via opiate

Influence of the Placebo Effect on Medical Cannabis and Cannabinoids $(\mu, \kappa, \delta)$ and cannabinoid receptors (CB1 and CB2), respectively, opium and psychoactive cannabis might pharmacologically induce/promote placebo analgesia. This might be mediated via OPMR1 (opium) and CB1 receptors (cannabis) in specific areas of the brain [18-20]. Data in humans using the CB1 receptor inverse agonist (antagonist) rimonabant suggest that placebo analgesic responses elicited by non-opioid pharmacological conditioning with NSAIDs are mediated by CB1 receptors [17], though the corresponding synaptic circuits remain unknown. In monkeys, CB1 receptors are abundant in the basal ganglia, for example, in the striatum, areas shown to have a key role in the placebo response [21].

The meaning response $[6,22]$, an ethnomedically more accurate term for the placebo effect, is a phenomenon that underlies meaningful pharmacotherapeutic interventions and was first investigated in detail in the 1970s by Levine et al. [23]. The meaning response contributes to the overall therapeutic effects of virtually all medicines, in addition to their pharmacotherapeutic actions. A placebo is an agent that has no pharmacotherapeutic action but can still exert therapeutic effects. There is most likely not a single placebo effect, but many, with different underlying biochemical mechanisms across different pathophysiological conditions and therapeutic interventions. For instance, it was shown that the functional missense variant Pro129Thr (C385A polymorphism) of the human gene encoding fatty acid amide hydrolase (FAAH), the major degrading enzyme of the endocannabinoid anandamide, is associated with a diminished placebo analgesia [24]. The same FAAH polymorphism is associated with emotional-motivational reactivity, among other neurophysiological parameters [25]. In addition to showing that individuals homozygous for the common Pro129/Pro129 FAAH genotype (about half of the population) showed larger placebo analgesia and improved mood, the study could also link the opioid system with the ECS in the context of placebo analgesia. As well as the opioid system and ECS, discrete dopaminergic and serotonergic signalling networks and cholecystokinin have been implicated in mediating placebo analgesia [20]. The underlying meaning response is based on the anticipation of the patient to be healed, which triggers yet poorly understood neurobiochemical processes that counteract inflammatory processes and pain and impact mood. In the context of cannabis, the likelihood of triggering a meaning response is higher if many people believe in its effectiveness, such as in the case of cannabidiol (CBD) which is currently promoted as food additive and safe THC surrogate, despite insufficient toxicological and 
clinical data [26]. The learning framework associated with the meaning response includes social, verbal, and conditioning cues [27]. Moreover, there is increasing evidence of the existence of placebo responders and nonresponders, which suggests a biochemical or even genetic basis for this effect [20]. In evidence-based medicine, clinical endpoints in properly executed randomized controlled clinical trials need to show that the efficacy of a drug is superior to the meaning response. In this context, placebos are inert and do not cause any molecular effect. In certain therapeutic areas, for example pain management or neuropsychiatric disorders, the meaning response is substantial and medicines are often marginally superior over placebo [28]. Today, researchers believe that the meaning response has a molecular basis, imprinted by a genetic makeup, the placebome [16, 20, 29-31]. However, to pharmacologically induce a meaning response poses a philosophical problem because such an effect is no longer a pure placebo effect as it can be pharmacologically triggered. Despite a clear link between the ECS and the meaning response, no studies have so far addressed the potential induction/modulation of this mechanism by $\mathrm{CB} 1$ receptor agonists (cannabinoids).

By deconstructing the meaning response, expectation, anxiety, and reward all seem to be involved, as well as learning [32]. These neurophysiological processes are partly modulated by the ECS, possibly at different levels of synaptic transmission and plasticity. Given the ethical issues related to placebo research in humans, suitable animal models would be desirable to study the role of the ECS and impact of cannabis and cannabinoids on the meaning response. Nolan et al. [33] found that conditioned (placebo) responding in rats show three of the hallmarks of placebo-induced analgesia: strong inter-animal variability in the response, suppression by the opiate antagonist naloxone, and a positive predictive relationship between the unconditioned analgesic effect and the conditioned (placebo) effect. In a more recent rat model for placebo analgesia, cue preference was shown to be mediated by reward learning via the dopaminergic system, whereas the expression of placebo analgesia was mediated by both the dopaminergic and opioid systems [34]. Conditioned placebo effects are more often reported in rodents, but the dog may also provide a promising model species [35]. Thus, animal models could potentially be useful to assess the role of psychoactive cannabinoids in placebo analgesia and placebo immunomodulation. To date, both the opiate system and ECS have been shown to be essential components underlying the meaning response, but so far only in the context of pain. Intriguing- ly, placebo and nocebo effects appear to be associated with opposite responses of dopaminergic and endogenous opioid neurotransmission in a distributed network of regions [36].

As recently pointed out by Casarett [37], there is growing acceptance of medical cannabis as a legitimate therapy but this acceptance has been driven by placebo-controlled trials that are flawed by inadequate blinding. Placebo cannabis produced by solvent extraction is available and the extraction process seems to retain the terpenoids so that the placebo material smells similar to the cannabis verum. However, the psychoactive and vasoactive effects of cannabis pose a considerable challenge for effective blinding because study participants who sense such effects will surmise that they are not receiving a placebo. On the other hand, the smell of cannabis could induce a strong meaning response based on learning, given that the participants are usually not cannabis-naïve. Indeed, it was shown that placebo nonresponding Parkinson patients can be turned into responders through learning from real drug treatment [38]. In fact, classical conditioning is the learning mechanism most frequently invoked to explain the meaning response [39]. These issues bias studies to overestimate the effectiveness of medical cannabis. Nevertheless, there is compelling evidence for the effectiveness of cannabis in neuropathic pain, spasticity associated with multiple sclerosis, and anorexia in the setting of serious illness. The current best evidence of cannabis clinical efficacy, based on a state of the art systematic meta-analysis of randomized clinical trials, are spasticity associated with multiple sclerosis, chronic pain, nausea and vomiting caused by chemotherapy, as well as appetite stimulation in cancer or HIV patients [40]. Patients in Europe and the US employ cannabis products experimentally for a surprisingly wide range of diseases, including cancer [41]. The spectrum of applications reflects the popular perception of cannabis as being a universal remedy. Patient-reported outcomes show that individuals suffering from pain, anxiety, and depression are using cannabis as a substitute for prescription drugs, particularly narcotics/opioids, and independent of whether they identify themselves as medical or nonmedical users [42]. However, to date there is no clinical evidence for the efficacy of cannabis in anxiety and depression from randomized controlled studies. Because of the moderate efficacy over placebo, some authors conclude that the potential benefits of cannabis-based medicines (herbal cannabis, plant-derived or synthetic THC) in chronic neuropathic pain might be outweighed by their potential harms [43]. Importantly, the term cannabis is unprecise
Gertsch 
as it refers to distinctly different phytopharmaceuticals (chemovars, extractions, etc.) derived from one plant species, thus causing controversies in the clinical development [44]. Given the association of CB1 receptor activation and the meaning response in non-opioid placebo analgesia, it is intriguing to speculate that psychoactive cannabis and cannabinoids enhance the meaning response biochemically, which could have clinical implications for placebo nonresponders (e.g., those carrying the FAAH C385A polymorphism), an aspect that has not been taken into account so far. Few botanical drugs have such persistent popular claims of exerting positive therapeutic effects as cannabis/cannabinoids. One possible reason to explain this could relate to the palliation effects of cannabis that might reflect a strong meaning response, in addition to its general pharmacological actions. Already in the 1950s, Henry and Beecher [45] postulated that placebos could have clinically significant effects. However, at that time, nothing was known about the now emerging underlying biological mechanisms that are not only evolutionarily conserved but also closely related to the ethnomedical history of humankind [46, 47]. Typically, a placebo was inert and inactive per definition and drugs were not attributed any meaning response. As pointed out by Moerman [22], the meaning response goes beyond clinical placebos, which convey the physicians' innermost feelings about medication and treatment; and the clinician can by her simple presence enhance the effectiveness of a medical procedure. In the case of psychoactive cannabis and cannabinoids, there could even be a molecular aspect to this. $\mathrm{CB} 1$ receptor activation might induce multiple effects, synergizing with CB2 receptor activation/modulation, a potentially protective mechanism in inflammatory conditions and modulation of the hypothalamic pituitary adrenal axis [48, 49]. Rather than being either a placebo or drug, cannabis might be a drug both conveying and inducing a meaning response. This may explain the rather broad palliative effects of cannabis that knowingly improve the quality of life of patients, but also the blurred boundaries between medical and recreational cannabis [50]. Beyond the aspired clinical endpoints upon cannabis treatment, the popularity of cannabis or cannabinoids as emerging panacea is likely unprecedented by any other herbal remedy. Nevertheless, future studies will have to address in more detail the contribution of placebo analgesia and possibly other physiological meaning responses in cannabis/cannabinoid treatment.

\section{References}

1 WHO (World Health Organization): The World Medicines Situation 2011. Traditional Medicines: Global Situation, Issues and Challenges, ed 3. Geneva, 2011, pp 1-14.

2 Allkin B: State of the World's Plants 2017; in Willis KJ (ed): Royal Botanical Gardens, Kew. London, 2017.

3 Smith-Hall C, Larsen HO, Pouliot M: People, plants and health: a conceptual framework for assessing changes in medicinal plant consumption. J Ethnobiol Ethnomed 2012;8:43.

4 Newman DJ, Cragg GM: Natural products as sources of new drugs over the 30 years from 1981 to 2010. J Nat Prod 2012;75:311-335.

5 Gertsch J: The metabolic plant feedback hypothesis: how plant secondary metabolites nonspecifically impact human health. Planta Med 2016;82:920-929.

6 Moerman DE, Jonas WB: Deconstructing the placebo effect and finding the meaning response. Ann Intern Med 2002;136:471-476.

7 Leonti M, Verpoorte R: Traditional Mediterranean and European herbal medicines. J Ethnopharmacol 2017;199:161-167.

8 Colalto C: What phytotherapy needs: Evidence-based guidelines for better clinical practice. Phytother Res 2018;32:413-425.

Influence of the Placebo Effect on Medical Cannabis and Cannabinoids
9 Xu Q, Bauer R, Hendry BM, Fan TP, Zhao Z Duez P, Simmonds MS, Witt CM, Lu A, Robinson N, Guo DA, Hylands PJ: The quest for modernisation of traditional Chinese medicine. BMC Complement Altern Med 2013;13: 132.

10 Pisanti S, Bifulco M: Modern history of medical cannabis: from widespread use to prohibitionism and back. Trends Pharmacol Sci 2017:38:195-198.

11 Maccarrone M, Bab I, Bíró T, Cabral GA, Dey SK, Di Marzo V, Konje JC, Kunos G, Mechoulam R, Pacher P, Sharkey KA, Zimmer A: Endocannabinoid signaling at the periphery: 50 years after THC. Trends Pharmacol Sci. 2015;36:277-296.

12 Howlett AC, Abood ME: CB1 and CB2 receptor pharmacology. Adv Pharmacol 2017;80: 169-206.

13 Mechoulam R: Looking back at cannabis research. Curr Pharm Des 2000;6:1313-1322.

14 Di Tomaso E, Cadas H, Gaillet S, Beltramo M, Desarnaud F, Venance L, Piomelli D: Endogenous lipids that activate cannabinoid receptors. Formation and inactivation. Adv Exp Med Biol 1997;407:335-340.
15 Di Marzo V, Piscitelli F: The endocannabinoid system and its modulation by phytocannabinoids. Neurotherapeutics 2015;12:692698.

16 Benedetti F, Carlino E, Pollo A: How placebos change the patient's brain. Neuropsychopharmacology 2011;36:339-354.

17 Benedetti F, Amanzio M, Rosato R, Blanchard C: Nonopioid placebo analgesia is mediated by CB1 cannabinoid receptors. Nat Med 2011; 17:1228-1230.

18 Tétreault P, Mansour A, Vachon-Presseau E, Schnitzer TJ, Apkarian AV, Baliki MN: Brain connectivity predicts placebo response across chronic pain clinical trials. PLoS Biol 2016; 14:e1002570.

19 Wager TD, Scott DJ, Zubieta JK: Placebo effects on human mu-opioid activity during pain. Proc Natl Acad Sci USA 2007;104: 11056-11061.

20 Hall KT, Loscalzo J, Kaptchuk TJ: Genetics and the placebo effect: the placebome. Trends Mol Med 2015;21:285-294.

21 Scott DJ, Stohler CS, Egnatuk CM, Wang H, Koeppe RA, Zubieta JK: Individual differences in reward responding explain placebo-induced expectations and effects. Neuron 2007; 55:325-336. 
22 Moerman DE: Against the "placebo effect:" a personal point of view. Complement Ther Med 2013;21:125-130.

23 Levine JD, Gordon NC, Fields HL: The mechanism of placebo analgesia. Lancet 1978;2: 654-657.

24 Peciña M, Martínez-Jauand M, Hodgkinson C, Stohler CS, Goldman D, Zubieta JK: FAAH selectively influences placebo effects. Mol Psychiatry 2014;19:385-391.

25 Conzelmann A, Reif A, Jacob C, Weyers P, Lesch KP, Lutz B, Pauli P: A polymorphism in the gene of the endocannabinoid-degrading enzyme FAAH (FAAH C385A) is associated with emotional-motivational reactivity. Psychopharmacology (Berl) 2012;224:573-579.

26 Iffland K, Grotenhermen F: An update on safety and side effects of cannabidiol: a review of clinical data and relevant animal studies. Cannabis Cannabinoid Res 2017;2:139-154.

27 Colagiuri B, Schenk LA, Kessler MD, Dorsey SG, Colloca L: The placebo effect: from concepts to genes. Neuroscience 2015;307:171190.

28 Pilla Reddy V, Kozielska M, Johnson M, Vermeulen A, de Greef R, Liu J, Groothuis GM, Danhof M, Proost JH: Structural models describing placebo treatment effects in schizophrenia and other neuropsychiatric disorders. Clin Pharmacokinet 2011;50:429-450.

29 Peciña M, Zubieta JK: Molecular mechanisms of placebo responses in humans. Mol Psychiatry 2015;20:416-423.

30 Pollo A, Carlino E, Benedetti F: Placebo mechanisms across different conditions: from the clinical setting to physical performance. Philos Trans R Soc Lond B Biol Sci 2011;366: 1790-1798.

31 Harrington A (ed): The Placebo Effect: An Interdisciplinary Exploration. Cambridge, MA, Harvard University Press, 1997.
32 Carlino E, Piedimonte A, Benedetti F: Nature of the placebo and nocebo effect in relation to functional neurologic disorders. Handb Clin Neurol 2016;139:597-606.

33 Nolan TA, Price DD, Caudle RM, Murphy NP, Neubert JK: Placebo-induced analgesia in an operant pain model in rats. Pain 2012;153: 2009-2016.

34 Lee IS, Lee B, Park HJ, Olausson H, Enck P, Chae Y: A new animal model of placebo analgesia: involvement of the dopaminergic system in reward learning. Sci Rep 2015;5:17140.

35 Sümegia Z, Gácsib M, Topálc J: Conditioned Placebo Effect in Dogs Decreases Separation Related Behaviours. Applied Animal Behaviour Science, 2014, vol 159, pp 90-98.

36 Scott DJ, Stohler CS, Egnatuk CM, Wang H, Koeppe RA, Zubieta JK: Placebo and nocebo effects are defined by opposite opioid and dopaminergic responses. Arch Gen Psychiatry 2008;65:220-231

37 Casarett D: The Achilles heel of medical cannabis research - inadequate blinding of placebo-controlled trials. JAMA Intern Med 2018; 178:9-10.

38 Benedetti F, Frisaldi E, Carlino E, Giudetti L, Pampallona A, Zibetti M, Lanotte M, Lopiano $\mathrm{L}$ : Teaching neurons to respond to placebos. J Physiol 2016;594:5647-5660.

39 Colloca L: Placebo, nocebo, and learning mechanisms. Handb Exp Pharmacol 2014; 225:17-35.

40 Whiting PF, Wolff RF, Deshpande S, Di Nisio M, Duffy S, Hernandez AV, Keurentjes JC, Lang S, Misso K, Ryder S, Schmidlkofer S, Westwood M, Kleijnen J: Cannabinoids for medical use: a systematic review and metaanalysis. JAMA 2015;313:2456-2473.
41 Bar-Lev Schleider L, Mechoulam R, Lederman V, Hilou M, Lencovsky O, Betzalel O, Shbiro L, Novack V: Prospective analysis of safety and efficacy of medical cannabis in large unselected population of patients with cancer. Eur J Intern Med 2018;49:37-43.

42 Corroon JM Jr, Mischley LK, Sexton M: Cannabis as a substitute for prescription drugs a cross-sectional study. J Pain Res 2017;10:989998

43 Mücke M, Phillips T, Radbruch L, Petzke F, Häuser W: Cannabis-based medicines for chronic neuropathic pain in adults. Cochrane Database Syst Rev 2018;3:CD012182.

44 Russo EB: Current therapeutic cannabis controversies and clinical trial design issues. Front Pharmacol 2016;7:309.

45 Henry K, Beecher MD: The powerful placebo. JAMA 1955;159:1602-1606.

46 Benedetti F: Drugs and placebos: what's the difference?: Understanding the molecular basis of the placebo effect could help clinicians to better use it in clinical practice. EMBO Rep 2014;15:329-332.

47 Shapiro AK, Shapiro E: The Powerful Placebo: From Ancient Priest to Modern Physician. Baltimore, Johns Hopkins University Press, 1997.

48 Pacher P, Mechoulam R: Is lipid signaling through cannabinoid 2 receptors part of a protective system? Prog Lipid Res 2011;50: 193-211.

49 Zoppi S, Madrigal JL, Caso JR, García-Gutiérrez MS, Manzanares J, Leza JC, García-Bueno $\mathrm{B}$ : Regulatory role of the cannabinoid CB2 receptor in stress-induced neuroinflammation in mice. Br J Pharmacol 2014;171:2814-2826.

50 Bostwick JM: Blurred boundaries: the therapeutics and politics of medical marijuana. Mayo Clin Proc 2012;87:172-186. 